\title{
Indole-3-Acetaldoxime-Derived Compounds Restrict Root Colonization in the Beneficial Interaction Between Arabidopsis Roots and the Endophyte Piriformospora indica
}

\author{
Pyniarlang L. Nongbri, ${ }^{1}$ Joy Michal Johnson, ${ }^{1}$ Irena Sherameti, ${ }^{1}$ Erich Glawischnig, ${ }^{2}$ \\ Barbara Ann Halkier, ${ }^{3}$ and Ralf Oelmüller ${ }^{1}$ \\ ${ }^{1}$ Institute of General Botany and Plant Physiology, Friedrich-Schiller-University Jena, Dornburger Str. 159, 07743 Jena, \\ Germany; ${ }^{2}$ Lehrstuhl für Genetik, Technische Universität München, Emil-Ramann-Str.8, 85350 Freising, Germany; ${ }^{3}$ VKR \\ Research Centre Pro-Active Plants, Department of Plant Biology and Biotechnology, Faculty of Life Sciences, University \\ of Copenhagen, Thorvaldsensvej 40, 1871 Frederiksberg C, Denmark
}

Submitted 29 March 2012. Accepted 17 May 2012.

The growth-promoting and root-colonizing endophyte $\mathrm{Pi}$ riformospora indica induces camalexin and the expression of CYP79B2, CYP79B3, CYP71A13, PAD3, and WRKY33 required for the synthesis of indole-3-acetaldoxime (IAOx)derived compounds in the roots of Arabidopsis seedlings. Upregulation of the mRNA levels by $P$. indica requires cytoplasmic calcium elevation and mitogen-activated protein kinase 3 but not root-hair-deficient 2, radical oxygen production, or the 3-phosphoinositide-dependent kinase 1/ oxidative signal-inducible 1 pathway. Because $P$. indicamediated growth promotion is impaired in cyp $79 B 2$ cyp $79 B 3$ seedlings, while pad3 seedlings-which do not accumulate camalexin-still respond to the fungus, IAOx-derived compounds other than camalexin (e.g., indole glucosinolates) are required during early phases of the beneficial interaction. The roots of cyp $79 B 2$ cyp $79 B 3$ seedlings are more colonized than wild-type roots, and upregulation of the defense genes pathogenesis-related (PR)-1, PR-3, PDF1.2, phenylalanine ammonia lyase, and germin indicates that the mutant responds to the lack of IAOx-derived compounds by activating other defense processes. After 6 weeks on soil, defense genes are no longer upregulated in wild-type, cyp $79 B 2$ cyp 7983 , and pad3 roots. This results in uncontrolled fungal growth in the mutant roots and reduced performance of the mutants. We propose that a long-term harmony between the two symbionts requires restriction of root colonization by IAOx-derived compounds.

Important secondary metabolites in members of order Brassicales are synthesized from tryptophan. Two functionally redundant cytochrome P450 enzymes (CYP79B2 and CYP79B3) convert tryptophan into indole-3-acetaldoxime (IAOx), an intermediate for the biosynthesis of indole glucosinolates (I-GLS), camalexin, other indole compounds such as indole acetonitrile, indole carboxylic acid derivatives, and, under specific condi-

P. L. Nongbri and J. M. Johnson contributed equally to the work.

Corresponding author: R. Oelmüller; E-mail: b7oera@uni-jena.de

* The $\boldsymbol{e}$-Xtra logo stands for "electronic extra" and indicates that four supplementary tables and one supplementary figure are published online and that Figure 5 appears in color online. tions, the plant hormone indole-3-acetic acid (IAA). Whereas camalexin is a true phytoalexin synthesized in the plant in response to pathogen infection or exposure to stress, I-GLS are both phytoanticipins present prior to induction as well as phytoalexins induced upon infection. The first committed step in I-GLS biosynthesis is the enzyme CYP83B1/SUR2 (Bak et al. 2001; Barlier et al. 2000; Hansen et al. 2001). The major IAOxmetabolizing enzyme in camalexin biosynthesis is CYP71A13, which catalyzes the formation of the intermediate indole acetonitrile (Nafisi et al. 2007), supposedly together with the homo$\log$ CYP71A12 required for camalexin exudation from roots (Millet et al. 2010). The thiazole ring of camalexin derives from the cysteine moiety of glutathione, which is conjugated with indole acetonitrile after activation (Böttcher et al. 2009; GeuFlores et al. 2011; Parisy et al. 2007; Su et al. 2011). The singlecopy gene $P A D 3 / C Y P 71 B 15$ encodes for an enzyme that catalyzes the final two steps in the camalexin pathway (Böttcher et al. 2009; Schuhegger et al. 2006)

The double cyp79B2 cyp79B3 mutant lacks I-GLS (Zhao et al. 2002) and is unable to induce camalexin synthesis (Glawischnig et al. 2004). Furthermore, it does not accumulate indole-3-carboxylic acid derivatives (Böttcher et al. 2009), secondary metabolites which are strongly induced by pathogen infections. IAA levels were unchanged in seedlings of this mutant (Sugawara et al. 2009), although some reduction was observed under heat stress (Zhao et al. 2002) and in root tips (Ljung et al. 2005). In summary, IAOx has an important role as a metabolic branch point regulating flux into I-GLS, camalexin, other secondary indole compounds, and IAA biosynthesis (Burow et al. 2010; Mikkelsen et al. 2009), and diversion of IAOx into one of the pathways may occur at the expense of the others (Bak et al. 2001; Glawischnig et al. 2004; Nafisi et al. 2006).

Production of camalexin is induced in response to a variety of exposures such as plant pathogens, including bacteria, fungi, and oomycetes (Glawischnig 2007; Rauhut and Glawischnig 2009), pathogen-associated molecular patterns (PAMPs), toxins (Gust et al. 2007; Qutob et al. 2006; Rauhut et al. 2009; Stone et al. 2000), and reactive oxygen species (ROS)-inducing abiotic stress (Van Breusegem et al. 2008). Camalexin exhibits cytotoxicity, particularly against eukaryotic pathogens (Rogers et al. 1996). Expression of the last enzyme of the camalexin biosynthetic pathway, PAD3, is regulated by a variety of signaling 
pathways. Crucial components are the mitogen-activated protein kinases (MPK) MPK3, MPK6 (Ren et al. 2008), and MPK4 (Qiu et al. 2008). MPK4 becomes activated in response to infection and phosphorylates MPK4 substrate 1 (MKS1) and the transcription factor WRKY33 in the nucleus, which ultimately allows WRKY33 to activate camalexin biosynthetic genes (Qiu et al. 2008). Upstream of MPK, the 3-phosphoinositide-dependent protein kinase 1 (PDK1)/oxidative signal-inducible 1 (OXI1) pathway is activated in response to various pathogens (Anthony et al. 2004, 2006; Rentel et al. 2004). OXI1 is required for full activation of MPK3 and MPK6 in response to many microbial pathogens or elicitors (Rentel et al. 2004; van der Luit et al. 2000; Yamaguchi et al. 2005). OXI1 phosphorylates and, thus, activates the downstream serine/threonine kinase PTI1-2 and also controls root hair growth (Rentel et al. 2004). OXI1 is activated by $\mathrm{H}_{2} \mathrm{O}_{2}$ and phospholipid signals via PDK1 (Anthony et al. 2006). PDK1 binds to different signaling lipids, including the second messenger phosphatidic acid, which accumulates in response to microbial infections or elicitor treatments (Deak et al. 1999; Hirt et al. 2011). Phosphatidic acid is mainly produced by phospholipase $\alpha 1$ in Arabidopsis roots, and a corresponding mutant contains severely reduced levels of this plant second messenger (Devaiah et al. 2006). PDK1 phosphorylates and, thus, activates OXI1 in Arabidopsis (Anthony et al. 2004) and rice (Matsui et al. 2010) or AvrPto-dependent Pto-interacting protein 3 (Adi3) in tomato (Devarenne et al. 2006).

Root-hair-deficient 2 (RHD2) is crucial for ROS production in roots, and inactivation of RHD2 compromises the expansion of root hair cells. Furthermore, $\mathrm{Ca}^{2+}$ influx is required for the cell elongation in roots, and rhd 2 mutants are defective in $\mathrm{Ca}^{2+}$ uptake. As a consequence, rhd2 mutants have short root hairs and stunted roots (Foreman et al. 2003). RHD6 controls root hair initiation and the RHD6 mutation can be rescued by auxin (Masucci and Schiefelbein 1994) or microbes producing auxinrelated compounds (Contreras-Cornejo et al. 2009). The observation that ROS induction and MPK3, MPK4, and MPK6 signaling activates camalexin biosynthesis suggests that ROSproducing enzymes and the PDK1/OXI1 pathway may be upstream in the signaling pathway to induce genes for IAOxderived compounds.

Piriformospora indica colonizes the roots of many plant species, thereby promoting growth and biomass production and conferring resistance against biotic and abiotic stress (Oelmüller et al. 2009; Peškan-Berghöfer et al. 2004). The beneficial inter-
A

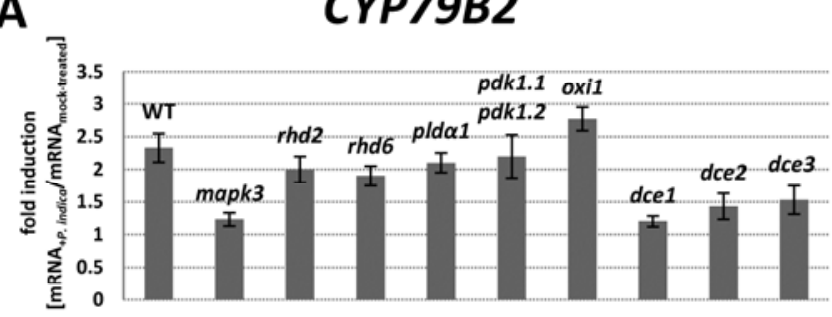

C

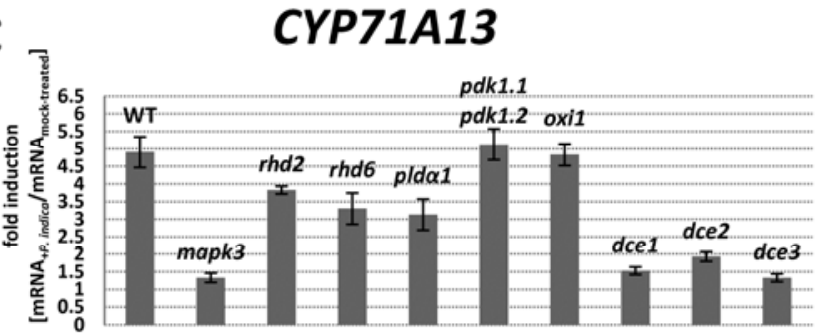

E

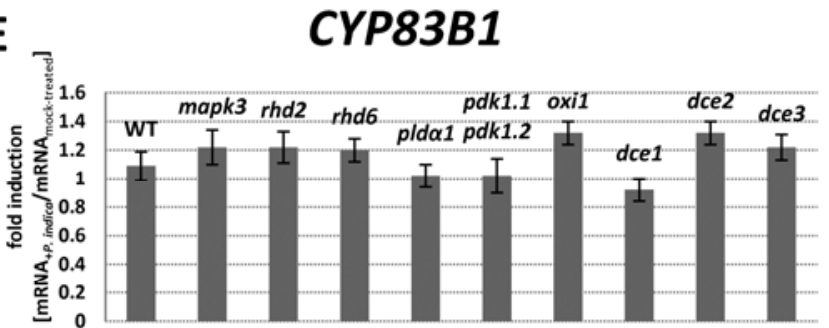

G

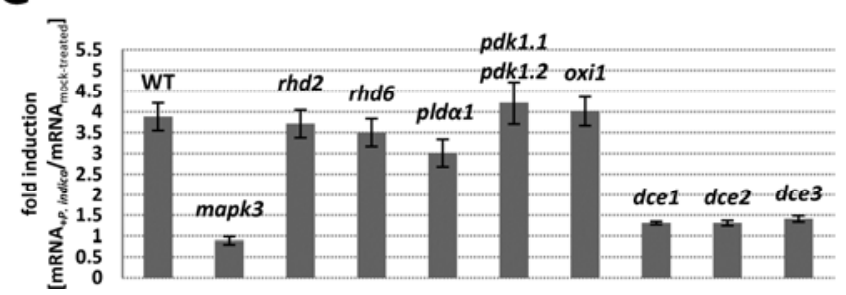

B

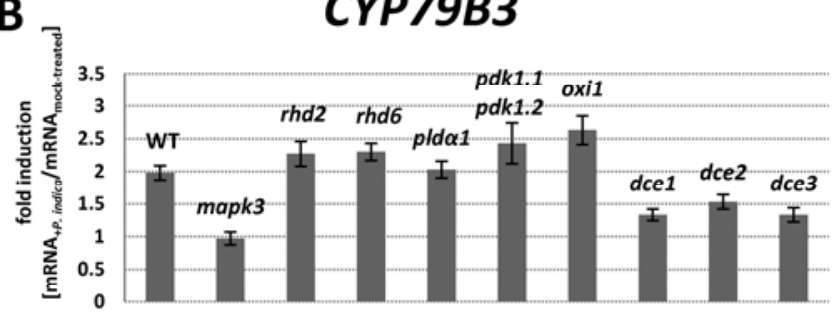

D

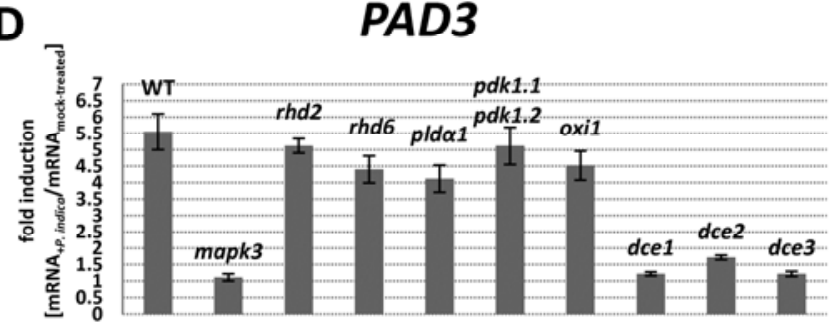

$\mathbf{F}$

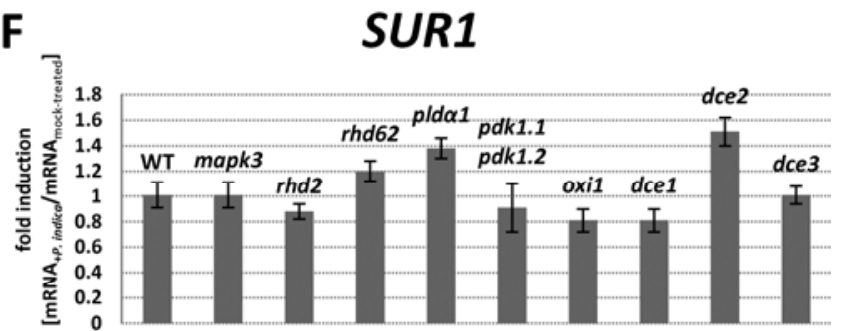

Fig. 1. Fold-induction of the mRNA levels for A, CYP79B2; B, CYP79B3; C, CYP71A13; D, PAD3; E, CYP83B1; F, SUR1; and G, WRKY33 by Piriformospora indica in Arabidopsis roots. RNA was isolated from the roots of wild-type (WT, Col 0) seedlings and different mutants as indicated which were either co-cultivated with $P$. indica for 14 days or mock treated. After real-time polymerase chain reaction analysis, the mRNA $+P$. indica $/ \mathrm{mRNA}_{\text {mock-treated }}$ ratio was calculated. Values are based on five independent biological experiments. Error bars were calculated as standard errors. Relative errors of the proportion are the sum of the individual relative errors. 
action between the endophytic fungus $P$. indica and Arabidopsis requires a balanced activation of defense processes, and mutants defective in specific defense-related genes are often unable to restrict fungal growth (Camehl and Oelmüller 2010; Camehl et al. 2010; Johnson and Oelmüller 2009; Sherameti et al. 2008). Here, we demonstrate that IAOx-derived indole compounds are crucial for the beneficial interaction between the two symbionts, and that these compounds restrict root colonization. We also demonstrate that $P$. indica-induced cytoplasmic calcium elevation and MPK3 but not $\mathrm{H}_{2} \mathrm{O}_{2}$, RHD2 and RHD6, and the PDK1/OXI1 pathway are required for the activation.

\section{RESULTS}

\section{Role of CYP79B2, CYP79B3, PAD3, and} camalexin in the interaction between $P$. indica and Arabidopsis seedlings.

Co-cultivation of Arabidopsis roots with $P$. indica on agar plates for 14 days resulted in a low but significant ( $t$ test, $n=5$, $P=0.025)$ induction of camalexin $\left(127 \pm 63 \mathrm{ng} \mathrm{g}^{-1}\right.$ fresh weight) compared with the mock-treated control $(50 \pm 10 \mathrm{ng}$ $\mathrm{g}^{-1}$ fresh weight), although it is synthesized in approximately two orders of magnitude lower concentrations compared with
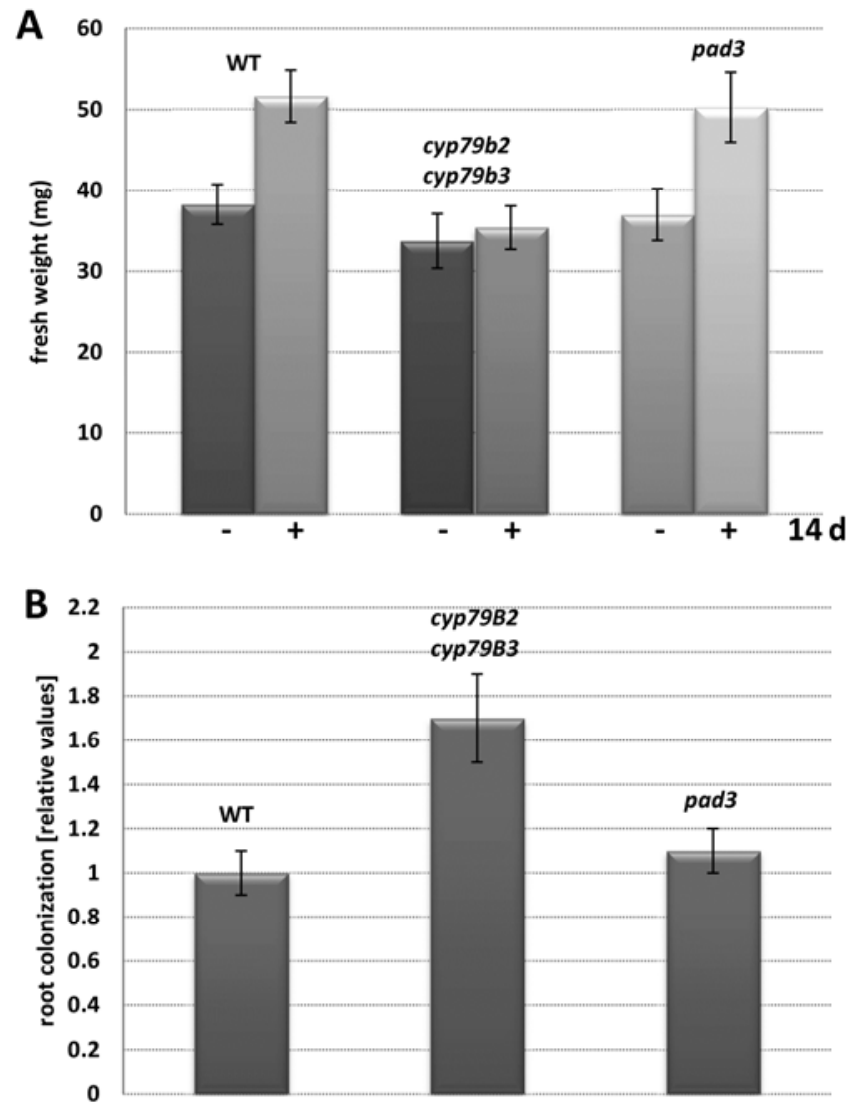

Fig. 2. A, Fresh weight of wild type (WT), cyp79B2 cyp79B3, and pad3 seedlings after 14 days of co-cultivation with Piriformospora indica or mock treatment. B, Increase of root colonization based on quantitative reverse-transcription polymerase chain reaction of cyp $79 B 2$ cyp79B3 and pad3 seedlings with respect to WT after 14 days of co-cultivation with $P$. indica. Root colonization was calculated as outlined in the text. Here, mRNA-based data are shown; however, they are not significantly different from DNA-based data, which are not shown. The value for WT was set as 1.0 and the other values are expressed relative to it. Bars represent standard errors, based on six independent biological experiments with 12 seedlings per treatment per experiment. Relative errors of the proportion $\left(\mathrm{mRNA}_{+ \text {P. indica }} / \mathrm{mRNA}_{\text {mock-treated }}\right)$ in B are the sum of the individual relative errors. roots infected with pathogens such as Plasmodiophora brassicae (Siemens et al. 2008). Also, the mRNA levels for CYP79B2, CYP79B3, CYP71A13 (Nafisi et al. 2007), PAD3, and WRK33 (Qiu et al. 2008) are upregulated in colonized wild-type (WT) roots, whereas those for CYP83B1 and SUR1 are not (Fig. 1A to G). This demonstrates that the genes for the synthesis of IAOx-derived compounds, including camalexin but not I-GLS, are targets of signals from the fungus.

In order to test whether IAOx-derived compounds are required for the beneficial interaction, we analyzed the growth response of cyp79B2 cyp79B3 and pad3 seedlings to $P$. indica. The weight of WT seedlings co-cultivated with $P$. indica on plant nutrient medium (PNM) plates for 14 days was approximately $35 \%$ higher compared with the mock-treated controls (Fig. 2A). The pad3 seedlings also responded to the fungus and the fresh weight was promoted similar to WT. However, the weight of $P$. indica-colonized cyp79B2 cyp79B3 seedlings was not significantly different from the mock-treated control (Fig. 2A). This demonstrates that camalexin synthesis is not essential for early processes during $P$. indica-mediated growth promotion and suggests that IAOx-derived compounds other than camalexin are required for the beneficial interaction.

Because camalexin exhibits cytotoxicity (Rogers et al. 1996), we tested whether it influences root colonization by $P$. indica. Therefore, the $P$. indica translation elongation factor 1 (Pitef1) DNA and mRNA levels relative to the plant glycerinaldehyde-3-phosphate dehydrogenase C2 (AtGAPC2) DNA and mRNA levels were determined in colonized WT, cyp79B2 cyp79B3, and pad3 plants. Colonization of the cyp79B2 cyp $79 B 3$ but not pad3 mutant roots was higher than that of WT roots (Fig. 2B). The data shown for pad3 colonization are consistent with those published by Jacobs and associates (2011). Furthermore, they showed that pen2-1 (defective in another enzyme linked to IAOx metabolism) displayed higher colonization. Because the Pitefl/AtGAPC2 ratios were almost identical when the polymerase chain reactions (PCRs) were performed with DNA or with cDNA synthesized from mRNA of the colonized roots, the fungus is alive in the roots and expresses the Pitefl gene. We also stained fungal spores in the roots and found the same colonization pattern for the WT and the mutants (Fig. 3). Counting of the spores in a 1-cm segment ( $1 \mathrm{~cm}$ from root tip) confirmed the data from Figure $2 \mathrm{~B}$. Analysis of 120 seedlings showed that cyp79B2 cyp79B3 roots (Fig. 3C and D) contain $59 \pm 8$ spores $/ \mathrm{cm}$, WT roots contain $39 \pm 4$ spores $/ \mathrm{cm}$, and pad 3 roots contain $37 \pm 5$ spores $/ \mathrm{cm}$. In all seedlings, spores are often associated with the root tips (Fig. 3B and D).

In colonized mutant roots, we observed a moderate but significant upregulation of plant defense genes (Fig. 4A to C), and this was more pronounced in cyp79B2 cyp $79 B 3$ than in pad3 plants. In particular, $P D F 1.2$ and germin were strongly upregulated in cyp79B2 cyp $79 B 3$ roots (Fig. 4A and B). Comparison of Figures 2 and 4 demonstrates that higher root colonization rates correlate with the activation of defense genes and the loss of benefits for the plants. This suggests that metabolites synthesized by the CYP79B enzymes restrict growth of $P$. indica.

\section{Cytoplasmic $\mathrm{Ca}^{2+}$ elevation and MPK3 but not} RHD2, RHD6, PLD $\alpha 1$, PDK1, or OXI1 are involved in the $P$. indica-induced upregulation of the mRNAs for CYP79B2, CYP79B3, CYP71A13, PAD3, and WRKY33.

Camalexin is induced by many plant pathogens in the roots and shoots of Arabidopsis. PAD3 activation requires MPK3 (Ren et al. 2008) and is stimulated by biotic and abiotic stresses leading to the formation of ROS (Van Breusegem et al. 2008). ROS production activates OXI1 which, in turn, is required for 
full activation of MPK3 and MPK6 (Rentel et al. 2004). In addition to ROS, OXI1 is also activated by the PDK1, after binding to the second messenger phosphatidic acid (Camehl et al. 2011).

To identify upstream components in the signaling cascade leading to PAD3, CYP79B2, CYP79B3, CYP71A13, and WRKY33 mRNA induction by $P$. indica in Arabidopsis roots, mutants of MPK3, the ROS-producing RHD2, the phosphatidic-acid-producing phospholipase D $\alpha 1$, the OXI-activating PDK1s, and ROS-activated OXI1 were compared with the WT after co-cultivation with $P$. indica (Fig. $1 \mathrm{~A}$ to $\mathrm{G}$ ). The rhd6 mutant was included to investigate the role of root hairs for the induction of the genes by the fungus. Furthermore, we included three genetically distinct Arabidopsis ethyl-methane-sulfonate mutants, called deficient in cytoplasmic calcium elevation (dce) 1 to $d c e 3$ which are impaired in inducing cytoplasmic $\mathrm{Ca}^{2+}$ elevation in response to the fungus and a fungal cell wall preparation (Fig. 5) (Vadassery et al. 2009). Because these mutants do not respond to the fungus in terms of growth promotion (unpublished data), the rapid increase in cytoplasmic $\mathrm{Ca}^{2+}$ elevation appears to be required for establishing the beneficial symbiosis.

PAD3 (Fig. 1D), CYP79B2 (Fig. 1A), CYP79B3 (Fig. 1B), $C Y P 71 A 13$ (Fig. 1C), and WRKY33 (Fig. 1G) were downregulated by $P$. indica in all mutants impaired in cytoplasmic $\mathrm{Ca}^{2+}$ elevation and in the mpk3 mutant, compared with WT, rhd2, rhd6, the pdk1.1 pdkl.2 double knock-out line, and oxil mutants (Fig. 1A to D and G) but CYP83B1 (Fig. 1E) and SUR1 (Fig. 1F) were not affected. Although phosphatidic acid might be a second messenger in $P$. indica-mediated growth promotion (Camehl et al. 2011) and phospholipase D $\alpha 1$ is a main producer of phosphatidic acid in Arabidopsis roots (Devaiah et al. 2006), the PAD3, CYP79B2, CYP79B3, CYP71A13, and WRKY33 mRNA levels are not significantly different in a mutant lacking phospholipase D $\alpha 1$ compared with the WT con- trol (Fig. 1A to D and G). Furthermore, we could not detect an increase in the ROS level in infected WT and mutant roots (Camehl et al. 2011; Vadassery et al. 2009). This suggests that $P$. indica stimulates the expression of these genes through a $\mathrm{Ca}^{2+}$ - and MPK3-dependent pathway but does not require production of ROS through the NADH oxidase RHD2 and the activity of the PDK1 and OXI1 (discussed below).

\section{PAD3 expression is induced locally by $P$. indica.}

We analyzed the expression of a PAD3 promoter::uidA fusion in mock-treated and colonized transgenic Arabidopsis seedlings using the root system in split petri dishes. Stimulation of $\beta$-glucuronidase (GUS) was only visible in root sections surrounded by fungal mycelium (Fig. 6A). A lower level of GUS activity was found in mock-treated roots (Fig. 6A). In particular, $P$. indica-induced GUS activity accumulated mainly in lateral roots during the early phase of interaction but, later, we noticed GUS staining in the main roots. To test whether this reflects the regulation of mRNA levels for IAOx-derived compounds, we isolated RNA from the roots and from preparations enriched in lateral roots and root hairs (discussed below) from colonized and uncolonized areas of the seedlings. The RNA extracted from fungus-exposed root areas after 14 days of co-cultivation of the two symbionts contained approximately three times higher mRNA levels for the $P$. indica-inducible PAD3, CYP79B2, CYP79B3, CYP71A13, and WRKY33 genes compared with the root areas which were not exposed to fungal hyphae. When RNA was extracted from the fungusexposed lateral root areas alone, we observed a much higher stimulation of these mRNA levels (Fig. 6B). Again, CYP83B1 and $S U R 1$ were not or much less upregulated compared with the other genes. This suggests that the former genes are induced locally by the fungus, preferentially in lateral roots and root hairs. We also analyzed relative GUS activity in lateral roots
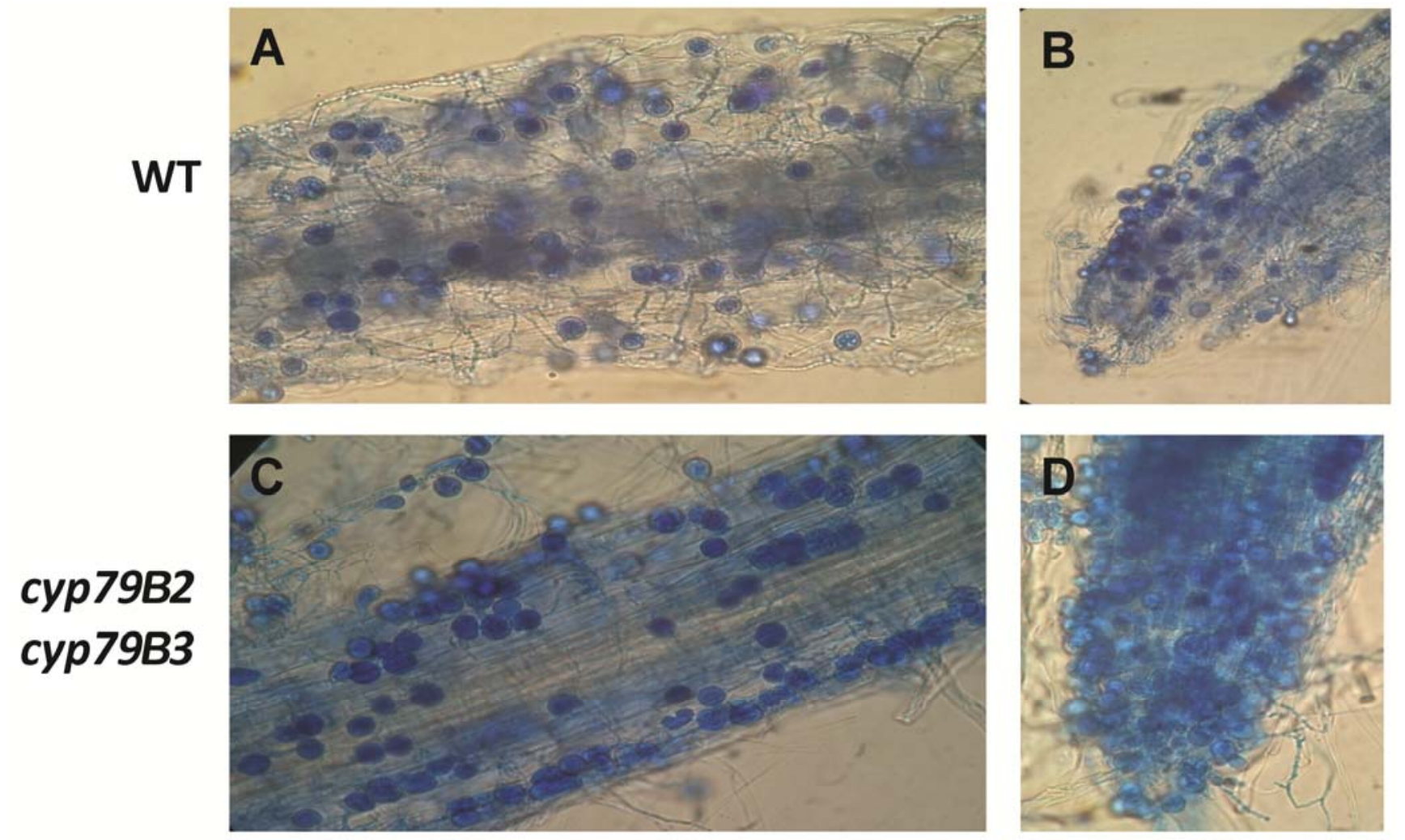

Fig. 3. Distribution of fungal spores in Arabidopsis $\mathbf{A}$ and $\mathbf{C}$, root segments (1 to $2 \mathrm{~cm}$ away from the root tip) or $\mathbf{B}$ and $\mathbf{D}$, at the root tip of $\mathbf{A}$ and $\mathbf{B}$, the wild type (WT) and $\mathbf{C}$ and D, cyp79B2 cyp79B3. Representative pictures for seedlings after 14 days of co-cultivation with Piriformospora indica on PNM plates. The colonization pattern was the same for WT and mutant seedlings on PNM plates and in soil, except that the spore densities differed. 
and root hairs at different time points after $P$. indica treatment (Fig. 6C). We noticed that, from $24 \mathrm{~h}$ onward, GUS expression was rapidly increased in $P$. indica co-cultivated lateral roots and root hairs (Fig. 6C).

\section{Role of CYP79B2, CYP79B3, PAD3, and camalexin in the interaction between $P$. indica and Arabidopsis plants in soil.}

After 14 days of co-cultivation on PNM medium (details below), colonized and mock-treated WT, cyp79B2 cyp79B3, and pad3 seedlings were transferred to soil. After 42 days, $P$. indica-infected WT plants produced $32 \pm 4 \%$ more shoot biomass than the mock-treated control. In contrast, the shoot biomass of infected cyp79B2 cyp79B3 and pad3 plants was reduced compared with the mock-treated control (Fig. 7A). Thus, long-term harmony between the two symbionts requires CYP79B2/CYP79B3 and PAD3.

After 42 days on soil (after 42 days, the vegetative phase was over, most of the plants flowered, and there was not any more camalexin increase), the camalexin level in the colonized WT roots was not higher than in the mock-treated control $(0.75 \pm$ $0.46 \mu \mathrm{g} \mathrm{g}^{-1}$ fresh weight; mock-treated control: $1.17 \pm 0.58 \mu \mathrm{g}$ $\mathrm{g}^{-1}$ fresh weight). However, when compared with seedlings, the camalexin levels in the roots of adult plants were five- to 10-fold higher. Thus, the overall amount of camalexin per fresh weight increased in the WT roots during the 42 days on soil but the small stimulatory effect of $P$. indica observed for the seedlings was no longer detectable for adult plants. Also the $P A D 3$, CYP79B2, CYP79B3, CYP71A13, and WRKY33 mRNA levels

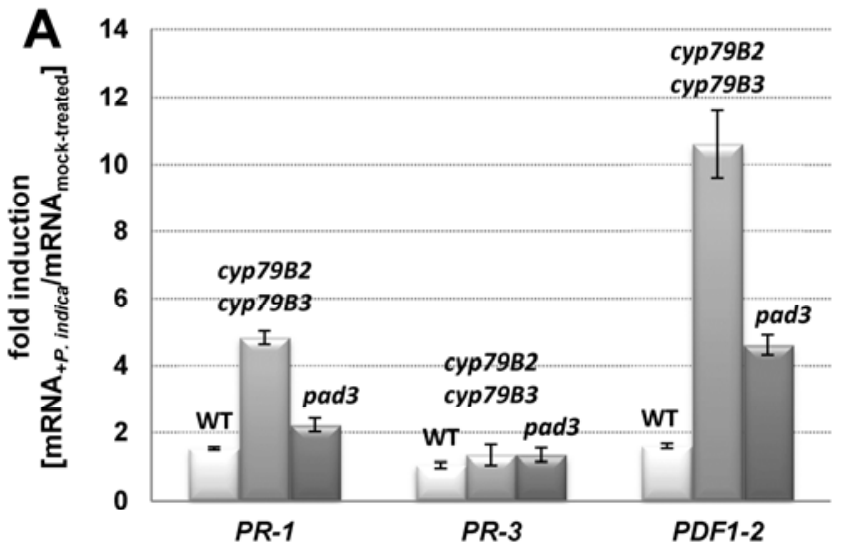

were no longer upregulated by the fungus in WT roots (Supplementary Table S2): in none of the experiments did we observe a significant stimulation by the fungus. Furthermore, pathogenesis-related $(P R)$ genes $(P R-1, P D F 1.2$, phenylalanine ammonia lyase $[P A L]$, and germin) which are highly upregulated in colonized roots of cyp79B2 cyp79B3 seedlings (Fig. 4A and B) were also upregulated in the roots of colonized adult cyp79B2 cyp79B3 and pad3 plants but at a lower scale (Fig. 7B1 and B2). The ROS-related RHD2 and the root-hair-controlling RHD6 genes are not regulated by $P$. indica (Fig. 7B3). We also could not detect ROS production in the roots of adult WT, cyp79B2 cyp79B3, and pad3 plants (Supplementary Table S3). Taken together, defense processes in the colonized mutant and WT roots of adult plants are not much activated by the fungus compared with the situation in the seedlings.

However, root colonization was much higher in the mutant plants compared with the WT (Fig. 7C). After 42 days in soil, the Pitef1 DNA or cDNA/AtGAPC2 DNA or cDNA ratios for the cyp79B2 cyp79B3 and pad3 plants were 11 and 5 times higher, respectively, than the ratio for WT plants (Fig. 7C). Kinetic analysis demonstrates that these ratios increased gradually with longer co-cultivation times on soil (Supplementary Table S4). Microscopic inspection of the colonization did not discover significant differences to the colonization pattern found for seedlings (Fig. 3): younger root sections were more colonized than older regions of the roots and spores were mainly found in association with lateral roots. Thus, the low level of defense gene activation in combination with the absence of IAOx-derived indole compounds promotes fungal

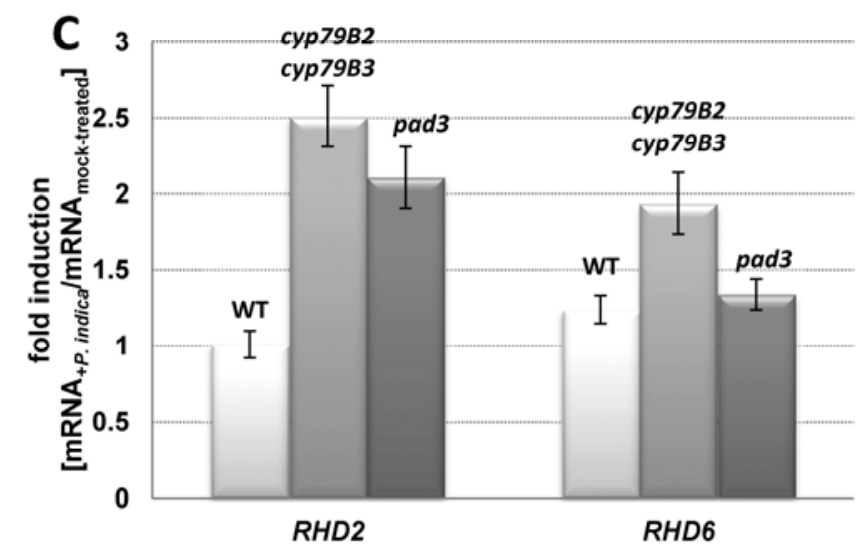

Fig. 4. Fold induction of the mRNA levels for pathogenesis-related $(P R)$ genes $\mathbf{A}, P R-1, P R-3$, and $P D F 1.2 ; \mathbf{B}$, phenylalanine ammonia lyase $(P A L)$ and germin; and C, root-hair-deficient (RHD) genes RHD2 and RHD6 by Piriformospora indica in Arabidopsis roots. RNA was isolated from the roots of wildtype (WT) and mutant (cyp79B2 cyp79B3 and pad3) seedlings which were either co-cultivated with $P$. indica for 14 days or mock treated. After real-time polymerase chain reaction analysis, the $\mathrm{mRNA}_{+P \text {. indica }} / \mathrm{mRNA}_{\text {mock-treated }}$ ratio was calculated. Data are based on five independent biological experiments with three replications. Error bars were calculated as standard errors. Relative errors of the proportion are the sum of the individual relative errors. 
growth (discussed below). Overcolonization of the roots might be the reason for the reduced benefits for the plants. This confirms that $P$. indica-mediated long-term benefits for the plants require CYP79B2/CYP79B3 and PAD3.

\section{DISCUSSION}

\section{Beneficial interaction between $P$. indica and}

\section{Arabidopsis requires IAOx-derived compounds.}

We demonstrated that IAOx-derived compounds are essential for initial steps in the beneficial interaction between $P$. indica and Arabidopsis, because seedlings of the cyp79B2 cyp $79 B 3$ double mutants do not respond to the fungal infection with growth promotion (Fig. 2A). Because pad3 seedlings respond to $P$. indica (Fig. 2A), camalexin seems not to be important during the initial phase of interaction. However, PAD3 is required during later stages (Fig. 7A).

Therefore, camalexin (Böttcher et al. 2009) and other IAOxderived compounds may be involved in independent processes in this symbiosis. Similar observations have been reported in different pathosystems. Schlaeppi and associates (2010) showed that a deficiency in either camalexin or I-GLS accumulation had only a minor effect on the disease resistance of Arabidopsis against Phytophthora brassicae infection, while cyp $79 B 2$ cyp79B3 was highly susceptible to $P$. brassicae. Sanchez-Vallet and associates (2010) have demonstrated that tryptophanderived secondary metabolites may have differential contributions in non-host resistance to necrotrophic and biotrophic pathogens. Analysis of additional mutants impaired in the synthesis of specific IAOx-derived secondary metabolites will help to understand their role in this beneficial symbiosis.

The higher degree of fungal colonization in the roots of cyp79B2 cyp79B3 seedlings (Fig. 2B) and adult cyp79B2 cyp79B3 and pad3 plants (Fig. 7C) and the initial activation of defense genes against the fungus in the roots of the cyp79B2 cyp79B3 seedlings suggest that IAOx and its derived compounds, including camalexin, participate in the control of fungal growth. Initially, the roots responded to the lack of IAOx and its derived compounds by activating other defense genes such as PR-1, PDF 1.2, PAL, and germin (Fig. 4A and B). However, this mechanism appears to be restricted to early phases of the symbiosis and is no longer active in adult plants (Fig. 7B1 and B2). In

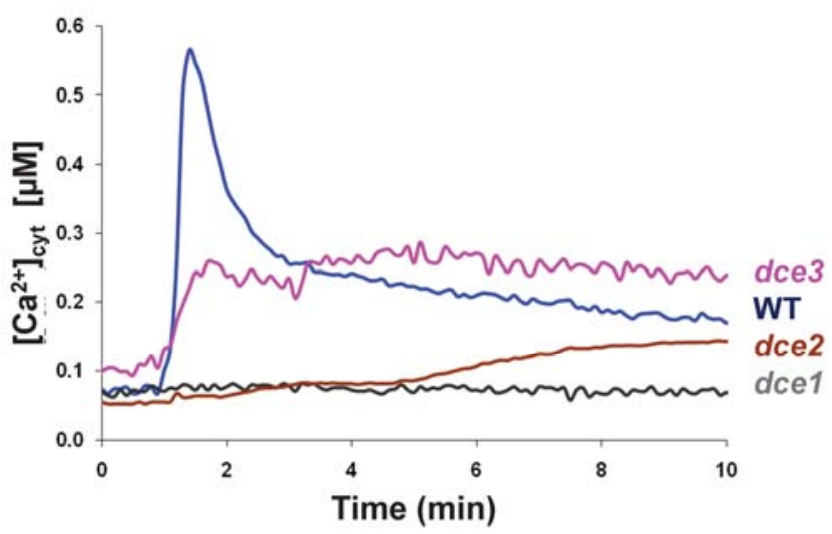

Fig. 5. Piriformospora indica cell wall extract (CWE) induces changes in cytosolic $\mathrm{Ca}^{2+}\left(\left[\mathrm{Ca}^{2+}\right]_{\text {cyt }}\right)$ levels in the roots of apoaequorin-transformed Arabidopsis wild-type (WT) seedlings or in the roots of three Arabidopsis mutants, deficient in cytoplasmic calcium elevation (dce) 1 to dce 3 . $\left[\mathrm{Ca}^{2+}\right]_{\text {cyt }}$ elevation was induced by the application of $50 \mu \mathrm{l}$ of $\mathrm{CWE}$ to Arabidopsis roots. The $\left[\mathrm{Ca}^{2+}\right]_{\text {cyt }}$ was calculated from the relative light units (RLU) measured at 5-s integration times for $10 \mathrm{~min}$. In all the experiments, water was used as control and gave background readings. The four calcium signatures are representative of several hundred measurements (Vadassery and associates 2009). the roots of adult mutants, expression of these defense genes is much lower when compared with the expression in seedling's roots, either because the plant recognizes the microbe as a friendly symbiont and no longer activates defense genes or because the symbiont actively represses the host's defense response (Jacobs et al. 2011). The low level of defense might explain the high colonization rate and the loss of benefits for the adult mutants.

Although overall defense gene activation in WT and mutant roots by $P$. indica is relatively mild compared with pathogen infections, previous studies have demonstrated that it is required for the beneficial interaction. Disturbance of ethylene signaling (Camehl and Oelmüller 2010; Camehl et al. 2010) or manipulation of the abundance of the root myrosinase PYK10 (Sherameti et al. 2008) have severe consequences for the beneficial interaction and are associated with a partial shift from mutualism to parasitism. In agreement with these observations, a number of reports have demonstrated that mycorrhiza rely on a mild activation of defense responses (de Hoff et al. 2009; Fester and Hause 2005; Gutjahr and Paszkowski 2009; Herre et al. 2007; Martin et al. 2007; Pozo and Azcón-Aguilar 2007; Purin and Rillig 2008; Strack et al. 2003). IAOx and its derived compounds, including camalexin, may provide another example for a defense process that restricts growth of fungi in beneficial root symbioses.

In this context, comparison of the root colonization of the seedlings (Fig. 2B) and adult plants (Fig. 7C) is interesting. After 14 days of co-cultivation of the seedlings with the fungus on PNM plates, they were transferred to soil for an additional 42 days. Root colonization in adult WT roots was approximately $40 \%$ of that of WT seedlings (Figs. 2B and 7C) although, in both cases, the increase in fresh weight is $>30 \%$ relative to the mock-treated controls (Figs. 2A and 7A). This suggests that the $P$. indica-mediated growth response of the WT seedlings could probably be achieved by even less colonization of roots. Furthermore, the root colonization of adult cyp79B2 cyp $79 B 3$ plants is five times and that of adult pad3 plants three times higher than that of the WT seedlings in plates. This indicates that the degree of root colonization fluctuates, which has also been observed for mycorrhizal fungi (Kennedy 2010). On the other hand, comparison of these values with the increase in biomass during the 42 days on soil clearly indicates that the fungus propagates in WT and mutant roots and that the propagation is much stronger in mutant than in WT roots. The higher degree of colonization of the fungus in adult mutant plants leads to reduction of biomass, where the balance of interaction is shifted to a low level of parasitism. Finally, the calculated Pitef1/AtGAPC2 ratios did not change significantly for seedlings and adult plants regardless of whether they are based on cDNA or DNA levels (Supplementary Fig. S1). This suggests that the fungus is viable and expresses the Pitefl gene during growth on soil.

The split-root-system experiment in combination with the expression analysis of genes involved in the synthesis of IAOx and its derived products demonstrate that the $P$. indica-induced responses are local. The relative GUS activity was rapidly increased in $P$. indica co-cultivated lateral roots and root hairs (Fig. 6C) at an early phase of interaction (from 24 to $60 \mathrm{~h}$ ). No stimulatory response has been observed in the uninfected sections of the roots and in mock-treatment. The mRNA levels were much higher in infected lateral roots when compared with the mock treatment (Fig. 6B). Also, Kliebenstein and associates (2005) and Schuhegger and associates (2007) reported that camalexin synthesis genes are typically upregulated locally in proximity to the sites of pathogen infections, and both biotrophic and necrotrophic pathogens can induce camalexin biosynthesis. The local camalexin accumulation corresponds to a 
strong induction of tryptophan and camalexin biosynthetic genes (Schuhegger et al. 2006, 2007). It is believed that lesions of the infected tissue are a prerequisite for camalexin induction in nature, although an autoclaved yeast suspension (Raacke et al. 2006) and peptidoglucan preparations (Gust et al. 2007) can induce the phytoalexin synthesis in leaves without observed cell death. Deshmukh and associates (2006) and Jacobs and associates (2011) have demonstrated that root regions undergoing cell death are more colonized by $P$. indica than other regions. Therefore, the interaction occurs preferentially at sides with injured root cells. We observed that, other than $P$. indica, a cell wall preparation from the fungus that promotes plant growth (Vadassery et al. 2009) induces PAD3, CYP79B2, $C Y P 79 B 3, C Y P 71 A 13$, and WRKY33 mRNA levels in a doseand time-dependent manner in the roots of Arabidopsis seedlings (data not shown). Therefore, the response does not necessarily require local injuries of individual root cells (e.g., by hyphal penetration) but can also be induced by a $P$. indica- released microbe-associated molecular pattern (MAMP) that is present in the cell wall preparation. Our data suggest that the $P$. indica-induced response occur locally, although Truman and associates (2010) provided evidence for a role of indolederived compounds in the establishment and maintenance of systemic immunity. Pathogens and pathogenic MAMPs often induce ROS production via NADH oxidases. Because ROS can function as a rapid, long-distance, auto-propagating signal (Mittler et al. 2011) and because $P$. indica and the $P$. indicaderived cell wall extract does not induce ROS production (Camehl et al. 2011; Vadassery et al. 2009), we may observe only a local induction of the PAD3, CYP79B2, CYP79B3, CYP71A13, and WRKY33 mRNA levels.

\section{Plant signaling events}

for the $\boldsymbol{P}$. indica-induced camalexin synthesis.

Defense gene activation in pathogenic plant-microbe interactions is often initiated by the activation of a plasma-membrane
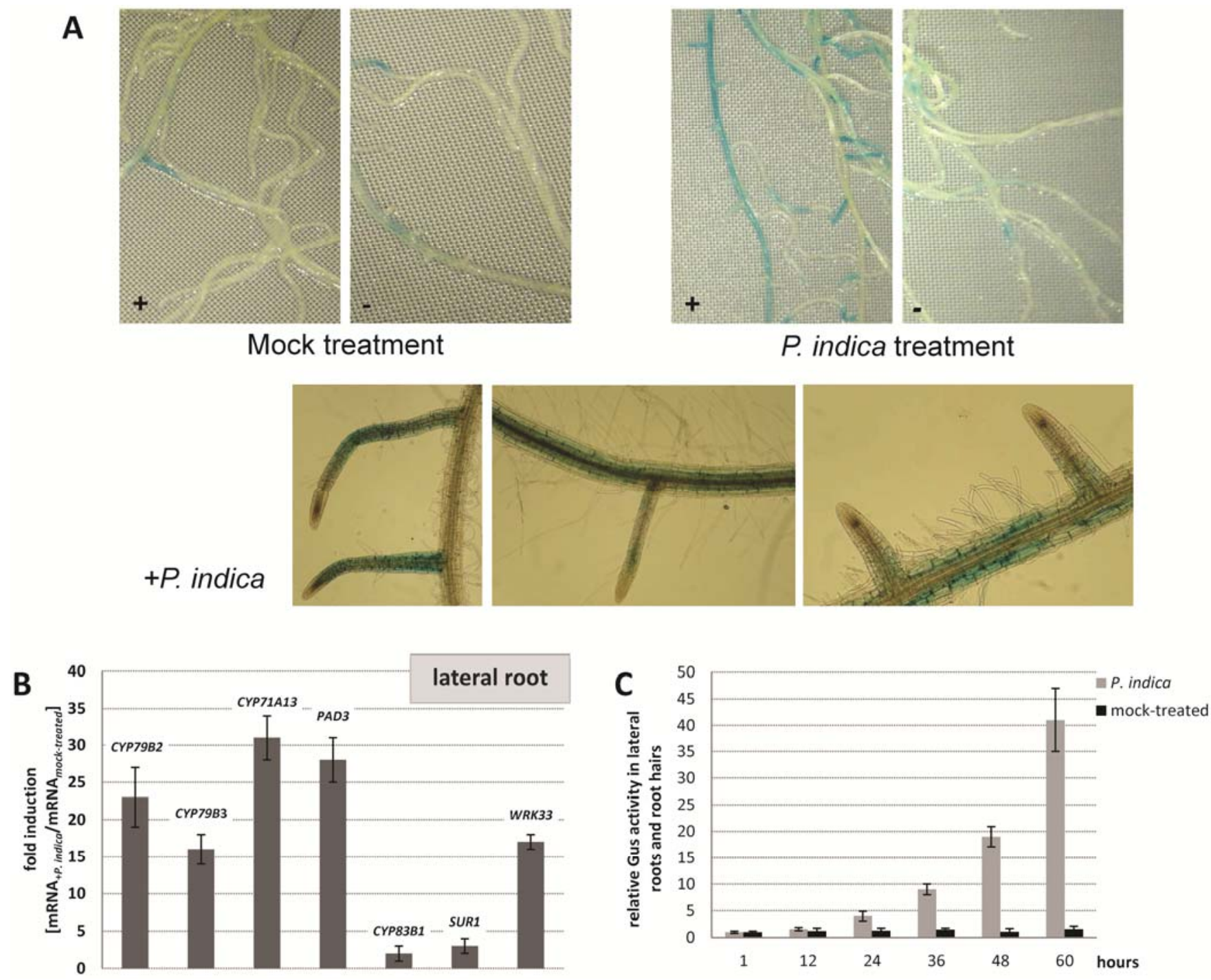

Fig. 6. A, $\beta$-Glucuronidase (GUS) staining of pad3::uidA roots in split petri dishes. Roots were not exposed (-) or exposed (+) to fungal hyphae. Mock treatment: without hyphae; Piriformospora indica treatment: plug was at the $(+)$ site of the split petri dish. A, Bottom pictures show enlargement of $P$. indica-exposed root sections from split petri dishes. B, Fold induction of the mRNA levels for CYP79B2, CYP79B3, CYP71A13, PAD3, CYP83B1, SUR1, and WRKY33 by $P$. indica in the lateral root and root hair preparation from Arabidopsis. RNA was isolated from the root material of wild-type (WT) seedlings which were either co-cultivated with $P$. indica for 14 days or mock treated. After real-time polymerase chain reaction analysis, the $\mathrm{mRNA}_{+P .}$ indical $\mathrm{mRNA}_{\text {mock-treated }}$ ratio was calculated. Data are based on four independent biological experiments with three replications. Error bars represent standard errors (SE). Relative errors of the proportion are the sum of the individual relative errors. C, Relative GUS activity in lateral roots and root hairs of mock-treated and $P$. indica-infected seedlings at the early phase of interaction (from 0 to $60 \mathrm{~h}$ ) of WT roots. Data are based on four independent biological experiments with 10 replications. Error bars represent SE. Relative errors of the proportion are the sum of the individual relative errors. 
localized receptor, followed by intracellular $\mathrm{Ca}^{2+}$ elevations, $\mathrm{H}_{2} \mathrm{O}_{2}$ production, and MPK3 or MPK6 phosphorylation. In pathogenic interactions, cytoplasmic $\mathrm{Ca}^{2+}$ elevation proceeds ROS production and MPK3 activation (Blume et al. 2000; Jabs et al. 1997; Kroj et al. 2003; Lee et al. 2004; Ligterink et al. 1997; Nürnberger et al. 1994; Zimmermann et al. 1997). Induction of the cytochrome P450 genes under study required MPK3 but appeared to be independent of $\mathrm{H}_{2} \mathrm{O}_{2}$-dependent processes leading to defense gene activation via the PDK1/OXI1 pathway (Fig. 1). Interestingly, three genetically distinct ethyl-methanesulfonate mutants that are impaired in inducing cytoplasmic $\mathrm{Ca}^{2+}$ elevation in response to $P$. indica and a cell wall extract from this fungus also fail to induce camalexin synthesis genes. Therefore, cytoplasmic $\mathrm{Ca}^{2+}$ elevation is required for $P$. indicainduced stimulation of the genes for the P450 enzymes and WRK33, similar to the signaling in pathosystems.

MPK3 inactivation prevents the induction of camalexin-synthesizing genes by $P$. indica almost completely (Fig. 1). This is in agreement with a previous observation that a cell-wall extract from the fungus phosphorylates MPK in a $\mathrm{Ca}^{2+}$-dependent manner (Vadassery et al. 2009). In pathogen-induced camalexin synthesis in leaves, MPK3 has an overlapping function with MPK6 and both kinases are required for full induction of camalexin biosynthesis (Ren et al. 2008). For instance, both
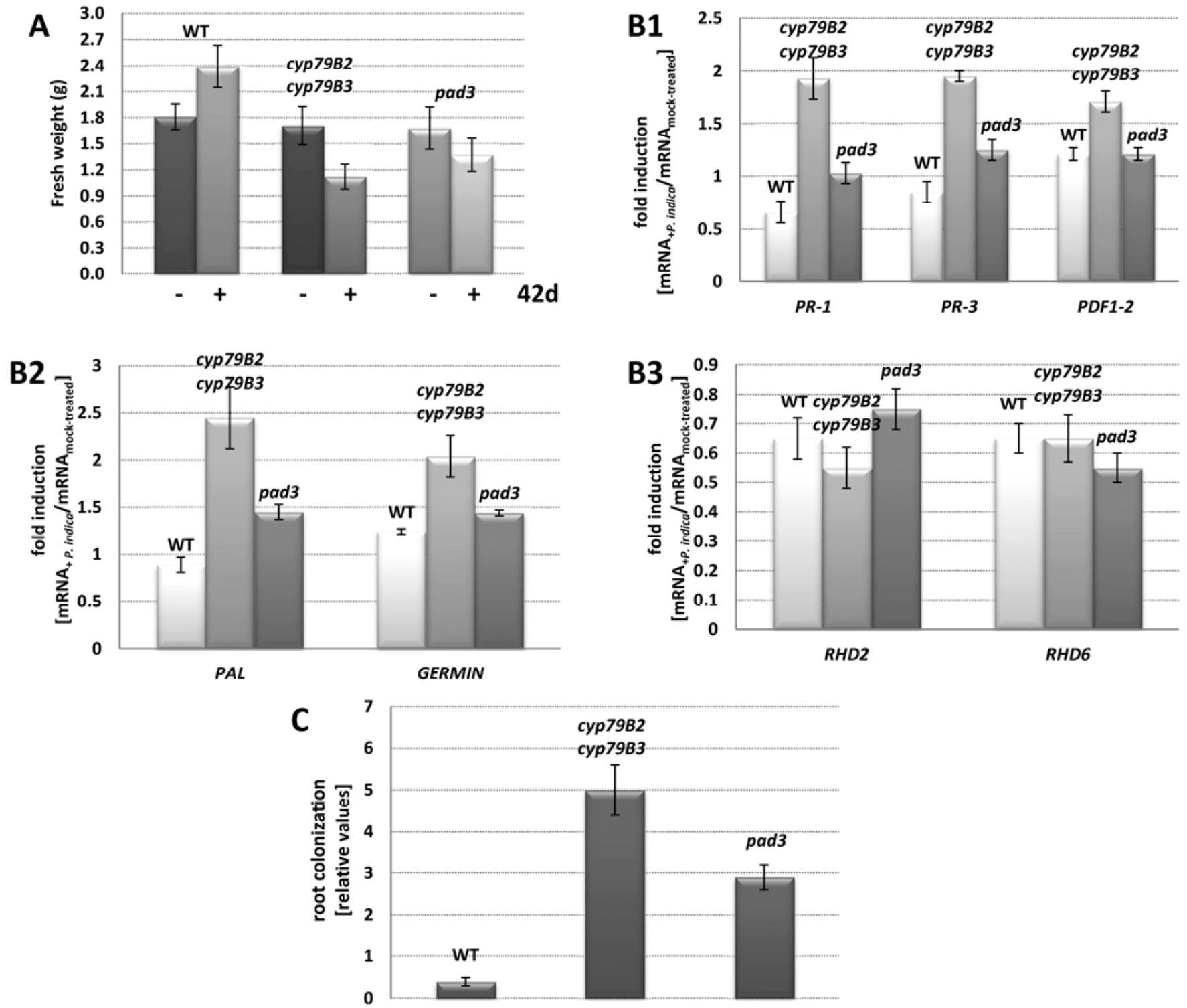

Fig. 7. A, Shoot fresh weight of the wild type (WT), cyp79B2 cyp79B3, and pad 3 of adult plants after 42 days in soil. WT and mutants seedlings were either co-cultivated with Piriformospora indica for 14 days or mock treated on PNM plates before transfer to soil. Standard errors (SE) are based on six independent biological experiments with 12 plants. B, Fold induction of the mRNA levels for pathogenesis-related $(P R)$ genes 1, $P R-1, P R-3$, and $P D F 1.2$; 2, phenylalanine ammonia lyase $(P A L)$ and germin; and 3, root-hair-deficient (RHD) genes RHD2 and RHD6 by P. indica in the roots of Arabidopsis WT, cyp79B2 cyp79B3, and pad3 plants. RNA was isolated from the roots of WT and mutant seedlings which were either co-cultivated with $P$. indica for 14 days or mock treated on PNM plates before transfer to soil for 42 days. After real-time polymerase chain reaction analysis, the mRNA $+P$. indical $\mathrm{mRNA}_{\text {mock-treated }}$ ratio was calculated. Data are based on six independent biological experiments with three replications. Error bars represent SE. Relative errors of the proportion are the sum of the individual relative errors. C, Root colonization (relative values) of WT, cyp79B2 cyp79B3, and pad 3 plants, which were either co-cultivated with $P$. indica for 14 days on PNM plates or mock treated before transfer to soil for 42 days. Root colonization was calculated as outlined in the text. Here mRNA-based data are shown; however, they are not significantly different from DNA-based data. To allow comparison of the root colonization data of the adult plants shown here with those of the seedlings shown in Figure $2 \mathrm{~B}$, the value for the WT control in this graph is expressed relative to that for WT seedlings in Figure 2B, which was set as 1.0. Bars represent SE, based on six independent biological experiments with three replications. 
MPK3 and MPK6 are required for Botrytis cinerea-induced camalexin synthesis and subsequent limitation of fungal growth (Ren et al. 2008). Whether this is different for beneficial or rootspecific fungi remains to be determined. $C Y P 79 B 2, C Y P 79 B 3$, and $P A D 3$ expression in response to $P$. indica is relatively low compared with the regulation by pathogens, which might be caused by the involvement of an additional control mechanism (for instance, active gene repression by either the plant or the fungus) to ensure a peaceful co-existence between the two symbionts.

Elevated $\mathrm{H}_{2} \mathrm{O}_{2}$ levels lead to the activation of OXI1, followed by MPK3 and MPK6 and PTI1-2 phosphorylation and transcriptional activation of defense genes (Anthony et al. 2004, 2006; Rentel et al. 2004). OXI1, in turn, is also activated by pathogens and MAMPs via phospholipid signaling and PDK1 activation (Anthony et al. 2006). Our data indicate that activation of CYP79B2, CYP79B3, CYP71A13, PAD3, and WRKY33 by P. indica in roots is independent of $\mathrm{H}_{2} \mathrm{O}_{2}$ production, $\mathrm{H}_{2} \mathrm{O}_{2}$-initiated OXI1 signaling, and phosphatidic acid-activated PDK (Fig. 1). ROS is not produced in $P$. indica-colonized WT roots (Camehl et al. 2011; Vadassery et al. 2009). In agreement with this observation, $\mathrm{RHD} 2$, a major $\mathrm{H}_{2} \mathrm{O}_{2}$-producing $\mathrm{NADH}$ oxidase in roots, was not required for the activation of the P450 enzyme genes and WRKY33 (Fig. 1). This is in agreement with previous observations that the PDK1-OXI1 cascade is important for the beneficial interaction between $P$. indica and Arabidopsis but not involved in defense gene activation (Camehl et al. 2011).

In summary, production of IAOx-derived metabolites is activated by $P$. indica during early phases of the interaction. This requires cytoplasmic $\mathrm{Ca}^{2+}$ elevation and MPK3; therefore, the fungus may utilize the classical defense pathway in the host. $\mathrm{H}_{2} \mathrm{O}_{2}$ production and activation of the $\mathrm{H}_{2} \mathrm{O}_{2}$-dependent OXI1 pathway is not involved in this response. After the beneficial symbiosis is established, defense processes, including the activation of genes for IAOx-derived metabolite synthesis, are no longer stimulated. However, for long-term harmony between the two symbionts, WT levels of IAOx-derived compounds are required to restrict root colonization.

\section{MATERIALS AND METHODS}

\section{Growth conditions of plant and fungus.}

Arabidopsis thaliana WT (ecotype Columbia-0) and mutant seed were surface-sterilized and placed on petri dishes containing Murashige-Skoog (MS) nutrient medium (Murashige and Skoog 1962). The rhd2 line was obtained from V. Zarsky (Charles University, Prague); the rhd6 (N6347), pdk1.1 (N613251), and pdk1.2 (N820699) lines from the Nottingham Arabidopsis Stock Centre; $m p k 3$ from D. Scheel (Halle); and oxil from H. Hirt (Paris). The pdk1.1 pdkl.2 double knock-out lines and all other mutants were described by Camehl and associates (2011). Homozygozity of the seed used for these studies was confirmed with gene-specific primers as previously published elsewhere. After cold treatment at $4^{\circ} \mathrm{C}$ for $48 \mathrm{~h}$, plates were incubated for 10 days at $22^{\circ} \mathrm{C}$ under continuous illumination $\left(100 \mu \mathrm{mol} \mathrm{m} \mathrm{m}^{-2} \mathrm{~s}^{-1}\right)$. $P$. indica was cultured as described previously on Aspergillus minimal medium (Hill and Kaefer 2001). More detailed information has been published by Johnson and associates (2011b). To ensure that the beneficial effect remain constant during fungal propagation, spores were reisolated from freshly infected Arabidopsis roots every 6 months for further propagation of the fungal hyphae (Johnson et al. 2011b, section A2).

Co-cultivation experiments and estimation of plant growth.

Twelve days after the growth of seedlings on MS media, $A$. thaliana seedlings of equal sizes were selected for co-cultiva- tion experiments with or without $P$. indica. Co-cultivation was done as described by Johnson and associates (2011b, section $\mathrm{C} 1$, method 1). Because equal light intensity for each seedling is critical, it was checked weekly. Weights of seedlings were determined at 14 day after co-cultivation. For DNA and RNA isolation and gene expression studies, only roots were used.

\section{Split root system, enrichment of lateral roots with root hairs.}

Arabidopsis seedlings were grown on MS medium as described above. Then, plants were transferred on nylon membrane on split plates containing PNM medium. Half of the root system was posed to one-half of the plate with a fungal plug, while the other half was posed on other half of the plate. Mock treatment was done with a Kaefer medium plug. Both petri dishes without lids were kept in a larger petri dish for 14 days under the conditions described above to allow growth of the seedlings. Roots were harvested for RNA extraction. Alternatively, the two sections of the roots were cut separately from the aerial parts with a scalpel and dipped into liquid nitrogen for $1 \mathrm{~s}$. Under this condition, smaller lateral roots and root hairs broke away from the main root and were recovered for RNA extraction.

\section{Experiments on soil.}

At 14 days after co-cultivation with $P$. indica or mock treatment on PNM plates, the seedlings were transferred to pots with uninfected soil for an additional 42 days (Johnson et al. 2011b, section C2, method 1). For harvest, the soil was removed from the roots with distilled water prior to RNA extraction. Plant were grown in a temperature $\left(22^{\circ} \mathrm{C}\right)$ - and moisture-controlled room with light from the top $\left(80 \pm 10 \mu \mathrm{mol} \mathrm{m}^{-2} \mathrm{~s}^{-1}\right.$ at the pot level) under short-day conditions ( $8 \mathrm{~h}$ of light and $16 \mathrm{~h}$ of darkness). The light intensity was monitored weekly.

\section{Preparation of the cell wall extract from $P$. indica.}

The cell wall extract was prepared using the protocol of Anderson-Prouty and Albersheim (1975), with modifications as described by Johnson and associates (2011a). Mycelia from 14-day-old liquid cultures were homogenized using mortar and pestle in water at $5 \mathrm{ml} / \mathrm{g}$ of mycelia. The homogenate was filtered using a coarse-sintered glass funnel. The residue was homogenized three times with water, twice with chloroform/ methanol (1:1), and finally in acetone. This preparation was air dried for $2 \mathrm{~h}$ and the mycelial cell wall material was recovered. Elicitor fractions were prepared from mycelial cell walls by suspending $1 \mathrm{~g}$ in $100 \mathrm{ml}$ of water and autoclaving for $30 \mathrm{~min}$ at $121^{\circ} \mathrm{C}$. Autoclaving releases the active fraction. The suspension was centrifuged at 14,000 rpm for $10 \mathrm{~min}$, was filter-sterilized using a $0.22-\mu \mathrm{M}$ filter, and was concentrated to half. This fraction was further purified by passing it through a Reverse Phase Superclean LC-18 Cartridges (Sigma-Aldrich, Taufkirchen, Germany). The active fractions were collected and again concentrated to half (Johnson et al. 2011a).

\section{Gene expression.}

RNA was isolated from root tissue, including the lateral roots and the root hairs, and reverse-transcribed for real-time quantitative PCR analysis, using an iCycler iQ real-time PCR detection system and iCycler software (version 2.2; Bio-Rad, Munich). Total RNA was isolated from independent biological experiments of Arabidopsis roots. cDNA was synthesized using the Omniscript cDNA synthesis kit (Qiagen, Hilden, Germany) using $1 \mu \mathrm{g}$ of RNA. For the amplification of the reverse-transcription PCR products, iQ SYBR Green Supermix (Bio-Rad) was used according to the manufacturer's protocol in a final volume of $25 \mu \mathrm{l}$. The iCycler was programmed to $95^{\circ} \mathrm{C}$ for $2 \mathrm{~min}$; 
40 cycles of $95^{\circ} \mathrm{C}$ for $30 \mathrm{~s}, 57^{\circ} \mathrm{C}$ for $40 \mathrm{~s}$, and $72^{\circ} \mathrm{C}$ for $45 \mathrm{~s}$; $72^{\circ} \mathrm{C}$ for $10 \mathrm{~min}$; followed by a melting curve program of 55 to $95^{\circ} \mathrm{C}$ in increasing steps of $0.5^{\circ} \mathrm{C}$. All reactions were performed in triplicate. The mRNA levels for each cDNA probe were normalized with respect to the GAPC2 mRNA level. Fold-induction values of target genes were calculated with the $\triangle \triangle \mathrm{CP}$ equation of Pfaffl (2001) and related to the mRNA level of target genes in mock-treated roots, which were defined as 1.0. Primer pairs with product sizes between 150 and 170 bp are given in Supplementary Table S1.

\section{Root colonization.}

Roots from plates or soil were harvested and roots from soil were washed intensively with distilled water before RNA or DNA extraction. $P$. indica was monitored with a primer pair for the elongation factor 1 (Pitefl) (Bütehorn et al. 2000). The Pitefl cDNA/DNA levels were expressed relative to the plant GAPC2 cDNA/DNA levels. In order to ensure that the fungus was alive, the data presented in the manuscript were based on cDNA synthesized from RNA of the colonized roots. The same calculations were performed for PCR products obtained for fungal and root DNA. However, we did not observe significant differences between cDNA-based and DNAbased data. DNA isolation has been described previously (Camehl et al. 2011). Staining of hyphae and spores occurred with Trypan blue $(0.05 \%)$ prior to light microscopy (Johnson et al. 2011b).

\section{GUS assays for pad3::uidA lines.}

Two independent pad3 promoter::uidA lines were used for these experiments (Schuhegger et al. 2006). GUS staining was performed by transferring the nylon membrane with the seedlings (and hyphae) to a fresh petri dish prior to the application of the substrates, as described by Sherameti and associates (2002).

\section{Camalexin determination.}

The determination of camalexin concentrations has been described previously (Glawischnig et al. 2004). Five biological replicates were analyzed.

\section{$\mathrm{Ca}^{2+}$ measurements, isolation of $\mathrm{Ca}^{2+}$ mutants.}

Transgenic apoaequorin $A$. thaliana (Col-0) lines (Knight et al. 1997) were used for $\mathrm{Ca}^{2+}$ measurements. The roots were dissected from 14-day-old seedlings and reconstituted in $5 \mu \mathrm{M}$ coelenterazine (P.J.K. GmbH, Kleinblittersdorf, Germany) in the dark overnight at $21^{\circ} \mathrm{C}$. The luminescence counts obtained with a microplate luminometer (Luminoscan Ascent, version 2.4; Thermo Fisher Scientific, Schwerte, Germany) were calibrated using the equation by Rentel and Knight (2004) (Johnson et al. 2011a; Vadassery et al. 2009, appendix S1). The mutants were obtained after ethyl methanesulfonate mutagenesis. Approximately 450,000 individuals were screened with the cell wall extract from $P$. indica (J. M. Johnson and R. Oelmüller, unpublished). The three mutant lines used here were propagated on soil and M5 seed were used for these analyses. Crosses between the lines confirmed that they are not allelic.

\section{Data analysis.}

Data points represent the mean of six independent biological experiments with 12 to 24 seedlings or plants per treatment per experiment (if not otherwise stated). Samples were evaluated with a two-sample $t$ test $(+P$. indica or mock treated) and analyses of variance (comparison of all data sets). Percent promotion is the proportion of $x$ (value $+P$. indica) and $y$ (value mock-treated $_{\text {), and }}$ the relative error of the proportion is the sum of the individual relative errors (standard errors of the mean).

\section{ACKNOWLEDGMENTS}

Work was supported by the Jena School of Microbial Communication and the Deutsche Forschungsgemeinschaft (OE133/28-1). We thank M. Hitzenbichler, S. Mußbach, and C. Röppischer for excellent technical assistance; and our colleges for the mutant and transgenic lines used for these experiments.

\section{LITERATURE CITED}

Anderson-Prouty, A. J., and Albersheim, P. 1975. Host-pathogen interactions. VIII. Isolation of a pathogen-synthesized fraction rich in glucan that elicits a defense response in the pathogens host. Plant Physiol. 56:286-291.

Anthony, R. G., Henriques, R., Helfer, A., Mészáros, T., Rios, G., Testerink, C., Munnik, T., Deák, M., Koncz, C., and Bögre, L. 2004. A protein kinase target of a PDK1 signalling pathway is involved in root hair growth in Arabidopsis. EMBO (Eur. Mol. Biol. Organ.) J. 23:572-581.

Anthony, R. G., Khan, S., Costa, J., Pais, M. S., and Bögre, L. 2006. The Arabidopsis protein kinase PTI1-2 is activated by convergent phosphatidic acid and oxidative stress signaling pathways downstream of PDK1 and OXI1. J. Biol. Chem. 281:37536-37546.

Bak, S., Tax, F. E., Feldmann, K. A., Galbraith, D. W., and Feyereisen, R. 2001. CYP83B1, a cytochrome P450 at the metabolic branch point in auxin and indole glucosinolate biosynthesis in Arabidopsis. Plant Cell 13:101-111.

Barlier, I., Kowalczyk, M., Marchant, A., Ljung, K., Bhalerao, R., Bennett, M., Sandberg, G., and Bellini, C. 2000. The SUR2 gene of Arabidopsis thaliana encodes the cytochrome P450 CYP83B1, a modulator of auxin homeostasis. Proc. Natl. Acad. Sci. U.S.A. 97:14819-14824.

Blume, B., Nürnberger, T., Nass, N., and Scheel, D. 2000. Receptor-mediated rise in cytoplasmic free calcium required for activation of pathogen defence in parsley. Plant Cell 12:1425-1440.

Böttcher, C., Westphal, L., Schmotz, C., Prade, E., Scheel, D., and Glawischnig, E. 2009. The multifunctional enzyme CYP71B15 (PHYTOALEXIN DEFICIENT3) converts cysteine-indole-3-acetonitrile to camalexin in the indole-3-acetonitrile metabolic network of Arabidopsis thaliana. Plant Cell 21:1830-1845.

Burow, M., Halkier, B. A., and Kliebenstein, D. J. 2010. Regulatory networks of glucosinolates shape Arabidopsis thaliana fitness. Curr. Opin. Plant Biol. 13:348-353.

Bütehorn, B., Rhody, D., and Franken, P. 2000. Isolation and characterization of Pitef1 encoding the translation elongation factor EF-1 $\alpha$ of the root endophyte Piriformospora indica. Plant Biol. 2:687-692.

Camehl, I., and Oelmüller, R. 2010. Do ethylene response factors 9 and 14 repress $P R$ gene expression in the interaction between Piriformospora indica and Arabidopsis? Plant Signal Behav. 9:5-8.

Camehl, I., Sherameti, I., Venus, Y., Bethke, G., Varma, A., Lee, J., and Oelmüller, R. 2010. Ethylene signalling and ethylene-targeted transcription factors are required to balance beneficial and nonbeneficial traits in the symbiosis between the endophytic fungus Piriformospora indica and Arabidopsis thaliana. New Phytol. 185:1062-1073.

Camehl, I., Drzewiecki, C., Vadassery, J., Shahollari, B., Sherameti, I., Forzani, C., Munnik, T., Hirt, H., and Oelmüller, R. 2011. The OXI1 kinase pathway mediates Piriformospora indica-induced growth promotion in Arabidopsis. PLoS Pathog. 7:e1002051.

Contreras-Cornejo, H. A., Macías-Rodríguez, L., Cortés-Penagos, C., and López-Bucio, J. 2009. Trichoderma virens, a plant beneficial fungus, enhances biomass production and promotes lateral root growth through an auxin-dependent mechanism in Arabidopsis. Plant Physiol. 149:15791592.

Deak, M., Casamayor, A., Currie, R. A., Downes, C. P., and Alessi, D. R. 1999. Characterisation of a plant 3-phosphoinositide-dependent protein kinase- 1 homologue which contains a pleckstrin homology domain. FEBS (Fed. Eur. Biochem. Soc.) Lett. 451:220-226.

de Hoff, P. L., Brill, L. M., and Hirsch, A. M. 2009. Plant lectins: the ties that bind in root symbiosis and plant defence. Mol. Genet. Genomics 282:1-15

Deshmukh, S., Hückelhoven, R., Schäfer, P., Imani, J., Sharma, M., Weiss, M., Waller, F., and Kogel, K. H. 2006. . The root endophytic fungus Piriformospora indica requires host cell death for proliferation during mutualistic symbiosis with barley. Proc. Natl. Acad. Sci. U.S.A. 103:18450-18457.

Devaiah, S. P., Roth, M. R., Baughman, E., Li, M., Tamura, P., Jeannotte, R., Welti, R., and Wang X. 2006. Quantitative profiling of polar glycerolipid species from organs of wild-type Arabidopsis and a phospholipase Dalpha1 knockout mutant. Phytochemistry 67:1907-1924.

Devarenne, T. P., Ekengren, S. K., Pedley, K. F., and Martin, G. B. 2006. Adi3 is a Pdk1 interacting AGC kinase that negatively regulates plant 
cell death. EMBO (Eur. Mol. Biol. Organ.) J. 25:255-265.

Fester, T., and Hause, G. 2005. Accumulation of reactive oxygen species in arbuscular mycorrhizal roots. Mycorrhiza 15:373-379.

Foreman, J., Demidchik, V., Bothwell, J. H., Mylona, P., Miedema, H. Torres, M. A., Linstead, P., Costa, S., Brownlee, C., Jones, J. D., Davies, J. M., and Dolan, L. 2003. Reactive oxygen species produced by NADPH oxidase regulate plant cell growth. Nature 422:442-446.

Geu-Flores, F., Møldrup, M. E., Böttcher, C., Olsen, C. E., Scheel, D., and Halkier, .BA. 2011. Cytosolic $\gamma$-glutamyl peptidases process glutathione conjugates in the biosynthesis of glucosinolates and camalexin in Arabidopsis. Plant Cell 23:2456-2469.

Glawischnig, E. 2007. Camalexin. Phytochemistry 68:401-406.

Glawischnig, E., Hansen, B. G., Olsen, C. E., and Halkier, B. A. 2004 Camalexin is synthesized from indole-3-acetaldoxime, a key branching point between primary and secondary metabolism in Arabidopsis. Proc. Natl. Acad. Sci. U.S.A. 101:8245-8250.

Gust, A. A., Biswas, R., Lenz, H. D., Rauhut, T., Ranf, S., Kemmerling, B., Götz, F., Glawischnig, E., Lee, J., Felix, G., and Nürnberger, T. 2007. Bacteria-derived peptidoglycans constitute pathogen-associated molecular patterns triggering innate immunity in Arabidopsis. J. Biol. Chem. 282:32338-32348.

Gutjahr, C., and Paszkowski, U. 2009. Weights in the balance: jasmonic acid and salicylic acid signaling in root-biotroph interactions. Mol. Plant-Microbe Interact. 22:763-772.

Hansen, C. H., Du, L., Naur, P., Olsen, C. E., Axelsen, K. B., Hick, A. J., Pickett, J. A., and Halkier, B. A. 2001. CYP83b1 is the oxime-metabolizing enzyme in the glucosinolate pathway in Arabidopsis. J. Biol. Chem. 276:24790-24796.

Herre, E. A., Mejía, L. C., Kyllo, D. A., Rojas, E., Maynard, Z., Butler, A., and Van Bael, S. A. 2007. Ecological implications of anti-pathogen effects of tropical fungal endophytes and mycorrhizae. Ecology 88:550-558.

Hill, T. W., and Kaefer, E. 2001. Improved protocols for Aspergillus medium: trace elements and minimum media salt stock solutions. Fungal Genet. Newl. 48:20-21.

Hirt, H., Garcia, A. V., and Oelmüller, R. 2011. AGC kinases in plant development and defense. Plant Sign. Behavior 6:1030-1033.

Jabs, T., Tschöpe, M., Colling, C., Hahlbrock, K., and Scheel, D. 1997. Elicitor-stimulated ion fluxes and $\mathrm{O}_{2}^{-}$from the oxidative burst are essential components in triggering defence gene activation and phytoalexin synthesis in parsley. Proc. Natl. Acad. Sci. U.S.A. 94:4800-4805.

Jacobs, S., Zechmann, B., Molitor, A., Trujillo, M., Petutschnig, E., Likpa, V., Kogel, K. H., and Schäfer, P. 2011. Broad-spectrum suppression of innate immunity is required for colonization of Arabidopsis roots by the fungus Piriformospora indica. Plant Physiol. 156:726-740.

Johnson, J. M., and Oelmüller, R. 2009. Mutualism and parasitism: life in an unstable continuum. What can we learn from the mutualitic interaction between Piriformospora indica and Arabidopsis thaliana? Endocyt. Cell Res. 19:81-111.

Johnson, J. M., Nongbri, P. L., Sherameti, I., and Oelmüller, R. 2011a. Calcium signaling and cytosolic calcium measurements in plants. Endocyt. Cell Res. 21:64-76. http://zs.thulb.uni-jena.de/receive/jportal_jparticle_ 00231945. Published online.

Johnson, J. M., Sherameti, I., Ludwig, A., Nongbri, P.L., Sun, C., Lou, B., Varma, A., and Oelmüller, R. 2011b. Protocols for Arabidopsis thaliana and Piriformospora indica cocultivation-A model system to study plant beneficial traits. Endocyt. Cell Res. 21:101-113. http://zs.thulb.unijena.de/receive/jportal_jparticle_00247947. Published online.

Kennedy, P. 2010. Ectomycorrhizal fungi and interspecific competition: species interactions, community structure, coexistence mechanisms, and future research directions. New Phytol. 187:895-910.

Kliebenstein, D. J., Rowe, H. C., and Denby, K. J. 2005. Secondary metabolites influence Arabidopsis/Botrytis interactions: variation in host production and pathogen sensitivity. Plant J. 44:25-36.

Knight, H., Trewavas, A. J., and Knight, M. R. 1997. Calcium signalling in Arabidopsis thaliana responding to drought and salinity. Plant J. 12:1067-1078.

Kroj, T., Rudd, J. J., Nürnberger, T., Gabler, Y., Lee, J., and Scheel, D. 2003. Mitogen-activated protein kinases play an essential role in oxidative burst-independent expression of pathogenesis-related genes in parsley. J. Biol. Chem. 278:2256-2264.

Lee, J., Rudd, J. J., Macioszek, V. K., and Scheel, D. 2004. Dynamic changes in the localization of MAPK cascade components controlling pathogenesis-related (PR) gene expression during innate immunity in parsley. J. Biol. Chem. 279:22440-22448.

Ligterink, W., Kroj, T., zur Nieden, U., Hirt, H., and Scheel, D. 1997. Receptor-mediated activation of a MAP kinase in pathogen defence of plants. Science 276:2054-2057.

Ljung, K., Hull, A. K., Celenza, J., Yamada, M., Estelle, M., Normanly, J., and Sandberg, G. 2005. Sites and regulation of auxin biosynthesis in Arabidopsis roots. Plant Cell 17:1090-1104.
Martin, F., Kohler, A., and Duplessis, S. 2007. Living in harmony in the wood underground: ectomycorrhizal genomics. Curr. Opin. Plant Biol. 10:204-210.

Masucci, J. D., and Schiefelbein, J. W. 1994. The rhd6 mutation of Arabidopsis thaliana alters root-hair initiation through an auxin- and ethylene-associated process. Plant Physiol. 106:1335-1346.

Matsui, H., Miyao, A, Takahashi, A., and Hirochika, H. 2010. Pdk1 kinase regulates basal disease resistance through the OsOxi1-OsPtila phosphorylation cascade in rice. Plant Cell Physiol. 51:2082-2091.

Mikkelsen, M. D., Fuller, V. L., Hansen, B. G., Nafisi, M., Olsen, C. E., Nielsen, H. B., and Halkier, B. A. 2009. Controlled indole-3-acetaldoxime production through ethanol-induced expression of CYP79B2. Planta 229:1209-1217.

Millet, Y. A., Danna, C. H., Clay, N. K., Songnuan, W., Simon, M. D., Werck-Reichhart, D., and Ausubel, F. 2010. Innate immune responses activated in Arabidopsis roots by microbe-associated molecular patterns. Plant Cell 22:973-990.

Mittler, R., Vanderauwera, S., Suzuki, N., Miller, G., Tognetti, V. B., Vandepoele, K., Gollery, M., Shulaev, V., and Van Breusegem, F. 2011. ROS signaling: the new wave? Trends Plant Sci. 16:300-309.

Murashige, T., and Skoog, F. 1962. A revised medium for rapid growth and bioassays with tobacco tissue cultures. Physiol. Plant. 15:473-497.

Nafisi, M., Sønderby, I. E., Hansen, B. G., Geu-Flores, F., Nour-Eldin, H. H., Nørholm, M. H. H., Jensen, N. B., Li, J., and Halkier, B. A. 2006. Cytochromes P450 in the biosynthesis of glucosinolates and indole alkaloids. Phytochem. Rev. 5:331-346.

Nafisi, M., Goregaoker, S., Botanga, C. J., Glawischnig, E., Olsen, C. E., Halkier, B. A., and Glazebrook, J. 2007. Arabidopsis cytochrome P450 monooxygenase 71A13 catalyzes the conversion of indole-3-acetaldoxime in camalexin synthesis. Plant Cell 19:2039-2052.

Nürnberger, T., Nennstiel, D., Jabs, T., Sacks, W. R., Hahlbrock, K., and Scheel, D. 1994. High affinity binding of a fungal oligopeptide elicitor to parsley plasma membranes triggers multiple defence responses. Cell 78:449-460.

Oelmüller, R., Sherameti, S., Tripathi, S., and Varma, V. 2009. Piriformospora indica, a cultivable root endophyte with multiple biotechnological applications. Symbiosis 49:1-17.

Parisy, V., Poinssot, B., Owsianowski, L., Buchala, A., Glazebrook, J., and Mauch, F. 2007. Identification of PAD2 as a $\gamma$-glutamylcysteine synthetase highlights the importance of glutathione in disease resistance of Arabidopsis. Plant J. 49:159-172.

Peškan-Berghöfer, T., Shahollari, B., Giong, P. H., Hehl, S., Markert, C., Blanke, V., Varma, A. K., and Oelmüller, R. 2004. Association of Piriformospora indica with Arabidopsis thaliana roots represents a novel system to study beneficial plant-microbe interactions and involves early plant protein modifications in the endoplasmatic reticulum and at the plasma membrane. Physiol. Plant. 122:465-477.

Pfaffl, M. W. 2001. A new mathematical model for relative quantification in real-time RT-PCR. Nucleic Acids Res. 29:45.

Pozo, M. J., and Azcón-Aguilar, C. 2007. Unraveling mycorrhiza-induced resistance. Curr. Opin. Plant Biol. 10:393-398

Purin, S., and Rillig, M. C. 2008. Parasitism of arbuscular mycorrhizal fungi: reviewing the evidence. FEMS (Fed. Eur. Microbiol. Soc.) Microbiol. Lett. 279:8-14

Qiu, J. L., Fiil, B. K., Petersen, K., Nielsen, H. B., Botanga, C. J. Thorgrimsen, S., Palma, K., Suarez-Rodriguez, M. C., SandbechClausen, S., Lichota, J., Brodersen, P., Grasser, K. D., Mattsson, O. Glazebrook, J., Mundy, J., and Petersen, M. 2008. Arabidopsis MAP kinase 4 regulates gene expression through transcription factor release in the nucleus. EMBO (Eur. Mol. Biol. Organ.) J. 27:2214-2221.

Qutob, D., Kemmerling, B., Brunner, F., Küfner, I., Engelhardt, S., Gust, A. A., Luberacki, B., Seitz, H. U., Stahl, D., Rauhut, T., Glawischnig, E., Schween, G., Lacombe, B., Watanabe, N., Lam, E., Schlichting, R., Scheel, D., Nau, K., Dodt, G., Hubert, D., Gijzen, M., and Nürnberger, T. 2006. Phytotoxicity and innate immune responses induced by Nep1like proteins. Plant Cell 18:3721-3744.

Raacke, I. C., Rad, U. v., Mueller, M. J., and Berger, S. 2006. Yeast increases resistance in Arabidopsis against Pseudomonas syringae and Botrytis cinerea by salicylic acid-dependent as well as -independent mechanisms. Mol. Plant-Microbe Interact. 19:1138-1146.

Rauhut, T., and Glawischnig, E. 2009. Evolution of camalexin and structurally related indolic compounds. Phytochemistry 70:1638-1644.

Rauhut, T., Luberacki, B., Seitz, H. U., and Glawischnig, E. 2009. Inducible expression of a Nep1-like protein serves as a model trigger system of camalexin biosynthesis. Phytochemistry 70:185-189.

Ren, D., Liu, Y., Yang, K. Y., Han, L., Mao, G., Glazebrook, J., and Zhang, S. 2008. A fungal-responsive MAPK cascade regulates phytoalexin biosynthesis in Arabidopsis. Proc. Natl. Acad. Sci. U.S.A. 105:5638-5643.

Rentel, M. C., and Knight, M. R. 2004. Oxidative stress-induced calcium signalling in Arabidopsis. Plant Physiol. 135:1471-1479. 
Rentel, M. C., Lecourieux, D., Ouaked, F., Usher, S. L., Petersen, L. Okamoto, H., Knight, H., Peck, S. C., Grierson, C. S., Hirt, H., and Knight, M. R. 2004. OXI1 kinase is necessary for oxidative burst-mediated signalling in Arabidopsis. Nature 427:858-861.

Rogers, E. E., Glazebrook, J., and Ausubel, F. M. 1996. Mode of action of the Arabidopsis thaliana phytoalexin camalexin and its role in Arabidopsis-pathogen interactions. Mol. Plant-Microbe Interact. 9:748-757.

Sanchez-Vallet, A., Ramos, B., Bednarek, P., López, G., PiślewskaBednarek, M., Schulze-Lefert, P., and Molina, A. 2010. Tryptophanderived secondary metabolites in Arabidopsis thaliana confer non-host resistance to necrotrophic Plectosphaerella cucumerina fungi. Plant J. 63:115-127.

Schlaeppi, K., Abou-Mansour, E., Buchala, A., and Mauch F. 2010. Disease resistance of Arabidopsis to Phytophthora brassicae is established by the sequential action of indole glucosinolates and camalexin. Plant $\mathbf{J}$. 62:840-851.

Schuhegger, R., Nafisi, M., Mansourova, M., Petersen, B. L., Olsen, C. E., Svatos, A., Halkier, B. A., and Glawischnig, E. 2006. CYP71B15 (PAD3) catalyzes the final step in camalexin biosynthesis. Plant Physiol. 141:1248-1254

Schuhegger, R., Rauhut, T., and Glawischnig, E. 2007. Regulatory variability of camalexin biosynthesis. J. Plant Physiol. 164:636-644.

Sherameti, I., Nakamura, M., Yamamoto, Y. Y., Pfannschmidt, T., Obokata, J., and Oelmüller, R. 2002. Polyribosome loading of spinach mRNAs for photosystem I subunits is controlled by photosynthetic electron transport. Plant J. 32:631-639.

Sherameti, I., Venus, Y., Drzewiecki, C., Tripathi, S., Dan, V. M., Nitz, I., Varma, A., Grundler, F. M., and Oelmüller, R. 2008. PYK10, a beta-glucosidase located in the endoplasmatic reticulum, is crucial for the beneficial interaction between Arabidopsis thaliana and the endophytic fungus Piriformospora indica. Plant J. 54:428-439.

Siemens, J., Glawischnig, E., and Ludwig-Müller, J. 2008. Indole glucosinolates and camalexin do not influence the development of the clubroot disease in Arabidopsis thaliana. J. Phytopathol. 156:322337.

Stone, J. M., Heard, J. E., Asai, T., and Ausubel, F. M. 2000. Simulation of fungal-mediated cell death by fumonisin B1 and selection of fumonisin B1-resistant (fbr) Arabidopsis mutants. Plant Cell 12:1811-1822.
Strack, D., Fester, T., Hause, B., Schliemann, W., and Walter, M. H. 2003. Arbuscular mycorrhiza: biological, chemical, and molecular aspects. J. Chem. Ecol. 29:1955-1979.

Su, T., Xu, J., Li, Y., Lei, L., Zhao, L., Yang, H., Feng, J., Liu, G., and Ren, D. 2011. Glutathione-indole-3-acetonitrile is required for camalexin biosynthesis in Arabidopsis thaliana. Plant Cell 23:364-380.

Sugawara, S., Hishiyama, S., Jikumaru, Y., Hanada, A., Nishimura, T., Koshiba, T., Zhao, Y., Kamiya, Y., and Kasahara, H. 2009. Biochemical analyses of indole-3-acetaldoxime-dependent auxin biosynthesis in Arabidopsis. Proc. Natl. Acad. Sci. U.S.A. 106:5430-5435.

Truman, W. M., Bennett, M. H., Turnbull, C. G., and Grant, M. R. 2010. Arabidopsis auxin mutants are compromised in systemic acquired resistance and exhibit aberrant accumulation of various indolic compounds. Plant Physiol. 152:1562-1573.

Vadassery, J., Ranf, S., Drzewiecki, C., Mithöfer, A., Mazars, C., Scheel, D., Lee, J., and Oelmüller, R. 2009. A cell wall extract from the endophytic fungus Piriformospora indica promotes growth of Arabidopsis seedlings and induces intracellular calcium elevation in roots. Plant $\mathbf{J}$. 59:193-206.

Van Breusegem, F., Bailey-Serres, J., and Mittler, R. 2008. Unraveling the tapestry of networks involving reactive oxygen species in plants. Plant Physiol. 147:978-984.

van der Luit, A. H., Piatti, T., van Doorn, A., Musgrave, A., Felix, G. Boller, T., and Munnik, T. 2000. Elicitation of suspension-cultured tomato cells triggers the formation of phosphatidic acid and diacylglycerol pyrophosphate. Plant Physiol.123:1507-1516.

Yamaguchi, T., Minami, E., Ueki, J., and Shibuya, N. 2005. Elicitorinduced activation of phospholipases plays an important role for the induction of defense responses in suspension-cultured rice cells. Plant Cell Physiol. 46:579-587.

Zhao, Y., Hull, A. K., Gupta, N. R., Goss, K. A., Alonso, J., Ecker, J. R., Normanly, J., Chory, J., and Celenza, J. L. 2002. Trp-dependent auxin biosynthesis in Arabidopsis: involvement of cytochrome P450s CYP79B2 and CYP79B3. Genes Dev. 16:3100-3112.

Zimmermann, S., Nürnberger, T., Frachisse, J. M., Wirtz, W., Guern, J., Hedrich, R., and Scheel, D. 1997. Receptor-mediated activation of a plant $\mathrm{Ca}^{2+}$-permeable ion channel involved in pathogen defence. Proc. Natl. Acad. Sci. U.S.A. 94:2751-2755. 